\title{
Impact of mucosal biofilm and bony osteitis on chronic rhinosinusitis with nasal polyps
}

\author{
Hassan El Ibiary', Naglaa Samir ${ }^{1}$, Ehab Kamal ${ }^{1}$ and Tarek Ashmawy ${ }^{1 *}$ (D)
}

\begin{abstract}
Background: Chronic rhinosinusitis (CRS) is a common inflammatory disorder whose underlying etiopathogenesis has not yet been completely understood and appears to be multifactorial. Microbial biofilms and bony osteitis are gaining an increased concern as they are considered to be among the possible factors that contribute to the overall local inflammatory load in chronic rhinosinusitis (CRS). This study investigated the impact of mucosal biofilm and bony osteitis on the pathophysiology and severity of chronic rhinosinusitis with nasal polyps (CRSwNP).

Results: Forty-five CRSWNP patients performing functional endoscopic sinus surgery (FESS) and 10 control patients were involved in this cross-sectional study. Mucosal and bony specimens from ethmoid sinus were obtained for both light and scanning electron (SEM) microscopic examination. The histopathologic bony grade was positive in 40/45 of CRSwNP patients versus $6 / 10$ of the control patients $(P=0.300)$; histopathologic mucosal grade was $44 / 45$ versus $4 / 10(P<0.001)$, and tissue eosinophilia was $45 / 45$ versus $6 / 10(P<0.001)$; biofilm was positive in $37 / 45$ versus $4 / 10(P=0.012)$. The mean of the sinonasal outcome treatment score (SNOT)-22 is 39.8 versus 50.5 ( $P=0.067)$; Lund-Mackay score (LMS) is 19.6 versus $3.1(P<0.0001)$.

Conclusion: (1) Mucosal biofilms and osteitis were detected in patients undergoing FESS for CRSWNP and also in controls without CRS. This suggests that mucosal biofilms and osteitis may not alone be the etiology of CRS without other cofactors. The pathogenesis of biofilms could be related to host factors. (2) The high odds ratio and wide confidence interval in our study suggest that there is a statistically significant association between biofilm formation and CRSwNP. (3) The high grade of mucosal inflammation and tissue eosinophilia suggests the inflammatory load added by osteitis and bacterial biofilm (BBF).
\end{abstract}

Keywords: Chronic rhinosinusitis, Chronic rhinosinusitis with nasal polyps, Biofilm, Osteitis

\section{Background}

Mucosal biofilms and bony osteitis are gaining an increased concern as they are considered to be among the possible factors that contribute to the total local inflammatory load [1] in CRS. Bacterial biofilms (BBF) are highly organized 3-dimensional bodies constituted of groups of bacteria encased inside a protective extracellular polysaccharide matrix, which are recalcitrant to both antibiotic

\footnotetext{
* Correspondence: dr.tarek.ashmawy1989@gmail.com

'Department of Otorhinolaryngology, Faculty of Medicine, Ain Shams University, Cairo, Egypt

Full list of author information is available at the end of the article
}

therapy and host immune mechanisms [2]. With the use of a variety of techniques, BBF have been consistently showed on the mucosa of patients with CRS among an ever-expanding research body, with a prevalence of 30 to $80 \%$ [3-5], and their existence has been correlated with worse parameters of the disease, post-surgical results, a greater prevalence of infection recurrence, and an elevated sinonasal outcome test (SNOT)-22 score [4-8]. Their existence has also been associated with increased disease severity that is in mostly refractory to present treatment paradigms [4].

\section{Springer Open}

(c) The Author(s). 2020 Open Access This article is licensed under a Creative Commons Attribution 4.0 International License, which permits use, sharing, adaptation, distribution and reproduction in any medium or format, as long as you give appropriate credit to the original author(s) and the source, provide a link to the Creative Commons licence, and indicate if changes were made. The images or other third party material in this article are included in the article's Creative Commons licence, unless indicated otherwise in a credit line to the material. If material is not included in the article's Creative Commons licence and your intended use is not permitted by statutory regulation or exceeds the permitted use, you will need to obtain permission directly from the copyright holder. To view a copy of this licence, visit http://creativecommons.org/licenses/by/4.0/. 
Osteitis is the bone inflammation that is devoid of marrow space [9]. In CRS, it is still uncertain whether osteitis is triggered via direct bacterial invasion, which is still not elucidated in researches or possibly is secondary to mediators of inflammation $[9,10]$. The prevalence of osteitis is between 36 and $79 \%$ in patients with CRS depending on radiographic criteria, findings of singlephoton emission computerized tomography, or pathologic results [11-13]. The degree of bony osteitis was correlated with disease severity and results after medical and surgical management $[13,14]$. Moreover, the existence of bony osteitis is correlated with a decreased potential for a better change in certain quality-of-life outcome values [9]. The aim of this study was to assess the impact of mucosal biofilm and bony osteitis on the pathophysiology and severity of CRSwNP.

\section{Methods}

\section{Study design and population}

This is a cross-sectional study that was done in the Otorhinolaryngology Department between 1/2018 and 5/ 2019 which was formally approved by the Ethics Committee (registration-number: FMASU MD 466/2017). Informed consent was obtained from all the participants.

The study involved 2 groups; the first group was the CRSwNP group which included 45 patients who were diagnosed according to the European Position Paper on Rhinosinusitis and Nasal Polyps guidelines [15], had failed optimal medical treatment, and underwent functional endoscopic sinus surgery (FESS). The second group included 10 control subjects with negligible or no subjective or objective evidence of CRS nor nasal polyps scheduled for nasal surgery (septoplasty and/or inferior turbinate reduction for nasal obstruction) were recruited as well. Exclusion criteria were patients with acute rhinosinusitis, fungal sinusitis, chronic rhinosinusitis without nasal polyps (CRSsNP), Wegner's granulomatosis, and other granulomatous diseases, cystic fibrosis, Kartagener syndrome, and other genetic and immune disorders and who underwent previous endoscopic sinus surgery.

\section{Collection of clinical data}

Preoperative collection of data included demographic features, Lund-Mackay computed tomography (CT) score, Rasp endoscopic grade, SNOT-22 score, aspirin sensitivity, systemic (granulomatous) diseases, previous FESS, smoking habit, allergic rhinitis, and bronchial asthma.

\section{Tissue preparation for osteitis and mucosal assay}

A tissue biopsy was taken from the ethmoidal bone with the overlying mucosa and polypoidal tissue during FESS, which were fixed into formalin (10\%) for $2 \mathrm{~h}$ followed by paraffin inclusion. Paraffin sections were cut at 4 microns thick and subjected to routine hematoxylin and eosin staining. Microscopic review was performed using a binocular light microscope. The microscopic slides were examined to assess the degree of mucosal and bony affection according to the criteria published by Biedlingmaier et al. [16] and to detect the number of present mucosal eosinophils. Eosinophils were calculated in the areas of richest cellular infiltrate to be sure that patients were categorized consistently based on the foci of highest inflammation. The eosinophil count was reported in each reticle field at $400 \times$ power and recorded as an absolute number per high power field. The degree of eosinophilia was classified according to Snidvongs et al. [17] as low eosinophilia $(<5$ per high power field [HPF]), moderate eosinophilia (5 to 10 per HPF), and high eosinophilia (> 10 per $\mathrm{HPF}$ ).

\section{Biofilm assay}

Biofilm was detected by means of SEM. Blocks of nasal samples were prepared for examination. Fixation and dehydration techniques were done using the tissue processor model (A-1170), where 6 to $8 \mathrm{~mm}^{2}$ of nasal specimens was cut. The squares were then fixed by submerging in $2.5 \%$ glutaraldehyde in phosphate-buffered saline (PBS) at $4{ }^{\circ} \mathrm{C}$ overnight. Fixed substance was allowed to acquire the temperature of the surrounding room and then washed in PBS (3 times, 10 min each) to take out the excess amounts of the fixative material. Substances dehydrated and were submerged via a graduated, $10 \%$ rising steps of ethanol, starting from 10 to $90 \%$, and lastly absolute ethanol. Desiccated samples were dried at the critical point. Then, the dried samples were fixed to $0.9 \mathrm{~mm}$ diameter stubs of copper using an electron microscopyspecific, conductive, double-adhesive carbon tape. Samples were subsequently coated with gold (about $50 \mathrm{~nm}$ thickness) via a Sputter Coater and then viewed by the highvacuum mode of a JEOL JSM-5500LV Scanning.

Structures characterized by 3-dimensional (3D) configuration and amorphous matrix that takes the shape of spherical or elliptical bodies were described as biofilms' evidence.

\section{Statistical analysis}

Data were analyzed using IBM๑ SPSS $\odot$ Statistics version 23 (IBMఠ Corp., Armonk, NY). Numerical variables were described as mean and standard deviation (SD), and inter-group differences were compared using the unpaired $t$ test. Categorical variables were shown as number and percentage, and differences between groups were compared using Pearson chi-squared test or Fisher's exact test. Ordinal data were compared using the chi-squared test for trend. Associations between nominal dichotomous were tested using the phi coefficient $(\phi)$. Point biserial correlation was used to evaluate the 
correlation between continuous variables and dichotomous variables. Rank biserial correlation was used to evaluate the correlation between ordinal variables and dichotomous variables. The Spearman rank correlation was used to test the correlation between ordinal variables. The point biserial $\left(r_{p b}\right)$, rank biserial $\left(r_{r b}\right)$, or Spearman's (rho, $\rho$ ) correlation coefficients are interpreted.

\section{Results}

As regards basic characteristics in CRSwNP patients and control group, there was only difference in the age distribution while there were no differences in the distribution of gender, allergy, asthma, aspirin sensitivity and smoking status, and SNOT-22 score between the two groups, but CRSwNP patients had statistically significant higher LMS (Tables 1, 2, and 3).

Regarding disease severity and symptom burden, there was a statistically significant difference between the 2 groups as regards the Lund-Mackay CT score $(P<$ $0.0001)$, Rasp endoscopy score $(P<0.001)$, but unexpectedly the mean SNOT-22 score is higher in the control group (50.5) than the CRSwNP group (39.8) with no significant difference statistically $(P=0.067)$ (Tables 2 and 3$)$

\section{BBF, osteitis, and mucosa in CRSwNP patients and controls}

Under SEM, 37/45 (82.2\%) were positive for biofilms in the CRSwNP group and $4(40 \%)$ in the control group $(P=$ 0.012) (Fig. 1). CRSwNP group has a higher rate of bony osteitis than that in the control group, based on histopathological findings $40 / 45$ (88.8\%) versus 6/10 (60\%), but the difference is not statistically significant $\left(\chi^{2}(1)=1.074\right.$, $P=0.300)$. The CRSwNP patients had more histopathological bony, mucosal changes assessed by Biedlingmaier's grade [16], and tissue eosinophilia evaluated by Snidvongs

Table 1 Basic characteristics in CRSwNP patients and controls

\begin{tabular}{llllll}
\hline & \multicolumn{3}{l}{ Group } & \multicolumn{2}{l}{} \\
\cline { 2 - 5 } & CRSwNP $(\boldsymbol{n}=45)$ & \multicolumn{2}{l}{ Control $(\boldsymbol{n}=10)$} & \\
\hline Variable & $n$ & $\%$ & $n$ & $\%$ & $P$ value* $^{*}$ \\
Smoking & 11 & 24.4 & 2 & 20.0 & 1.000 \\
Allergy & 16 & 35.6 & 1 & 10.0 & 0.148 \\
Bronchial asthma & 13 & 28.9 & 0 & 0.0 & 0.095 \\
Aspirin sensitivity & 3 & 6.7 & 0 & 0.0 & 1.000 \\
Age (years) - & $38.0 \pm 13.4$ & & $26.7 \pm 4.2$ & & $0.011 \wedge$ \\
Gender (M/F) & $24 / 21$ & & $5 / 5$ & & $1.000 \#$ \\
\hline
\end{tabular}

Data are number $(n)$ and percentage (\%)

*Fisher's exact test

-Data are mean \pm standard deviation (SD)

\#Fisher's exact test

$\wedge$ Independent samples $t$ test
[17] grade (Table 4) (Figs. 2 and 3). The bony osteitis of histopathological grade 4 (frank osteitis and bone destruction) and mucosal grade 4 (severe significant amounts of chronic inflammatory cellular infiltrate in the lamina propria) was not found in this study; there was statistically significant difference between the two groups regarding both the mucosal grading $(P$ value $<0.001)$ and tissue eosinophilia $(P$ value $<0.001)$.

\section{Correlation between BBF and histopathologic mucosal and bony grades}

The numbers of CRSwNP patients with different statuses of BBF, histopathologic osteitis, mucosal grading, and eosinophil count were shown in Table 4. There was no significant association between BBF and osteitis (Spearman rho $=0.205, P$ value $=0.176$ ). There was a weak positive correlation between bone grading and mucosal grading $($ Spearman rho $=0.345, P$ value $=0.020)$. There was positive correlation between bone grading and tissue eosinophilia grading (Spearman rho $=0.294, P$ value $=0.049$ ) There was also a very strong positive correlation between mucosal grading and tissue eosinophilia grading (Spearman rho $[\rho]=0.800, P$ value $<0.001)$. There is a statistically significant association between biofilm formation and CRSwNP with an odds ratio of 6.938 (95\% CI $=1.582$ to $30.417, P$ value $=0.010$ ) .

\section{Discussion}

This study reports the relationship between BBF and bony osteitis in patients with CRSwNP. In our study, histopathological features of bony osteitis were found in $88.8 \%$ of CRSwNP patients, $77.7 \%$ of the CRSwNP patients were positive for both bony osteitis and BBF, and only $6.6 \%$ of the CRSwNP patients were negative for both. Bony osteitis was also found in $60 \%$ of the control group which may explain the high SNOT-22 score in this group. Further association analysis showed no correlation between the presence of BBF and osteitis grading which may be attributed to the relatively large number of patients with bony osteitis in the control group or to the relatively small study population.

The idea of biofilm-induced CRS has been suggested by a number of researches [18-23] providing evidence that the expression of proteins on the cell surface, and some cytokines are up- or downregulated in local mucosa with BBF; however, the consensus is not reached. Regarding the osteitic bone and the overlying mucosa which BBF adheres to, it seems that both are stimulated by and act like a "depot" of inflammatory cytokines [10] which is reflected in our study by high mucosal grading and tissue eosinophilia.

Furthermore, the causal relationship between the BBF, osteitis, and local immune response is still undiscovered. Also, the definite mechanism of how bony osteitis 
Table 2 SNOT-22 score and Lund-Mackay CT score in both study groups

\begin{tabular}{|c|c|c|c|c|c|c|c|}
\hline \multirow[b]{2}{*}{ Variable } & \multicolumn{2}{|c|}{ CRSwNP $(\boldsymbol{n}=45)$} & \multicolumn{2}{|c|}{ Control $(\boldsymbol{n}=10)$} & \multirow[b]{2}{*}{ Difference } & \multirow[b]{2}{*}{$95 \% \mathrm{Cl}$} & \multirow[b]{2}{*}{$\boldsymbol{P}$ value $^{*}$} \\
\hline & Mean & SD & Mean & SD & & & \\
\hline SNOT-22 score & 39.8 & 17.5 & 50.5 & 9.2 & 10.7 & -0.8 to 22.2 & 0.067 \\
\hline Lund-Mackay CT score & 19.6 & 5.7 & 1.5 & 3.1 & -18.1 & -21.8 to -14.3 & $<0.0001$ \\
\hline
\end{tabular}

Data are mean and standard deviation (SD)

95\% Cl 95\% confidence interval

*Independent samples $t$ test

develops is yet not fully reached. Grossly, in areas where mucosal disease is persistent, the underlying bone is rendered poorly viable, which later on becomes thickened and develops neo-osteogenesis. This consequently results in increased scarring of the mucosa and potential for bony adhesions [14].

Further investigation is worth to detect the mechanism by which biofilm triggers an inflammatory response and the role of bony osteitis in the pathogenesis of CRS. Early studies supposed that CRS resistant patients' could make use of more extensive surgical procedures such as Denker's operation and the nasalization [1]. Since BBF and bony osteitis were potential etiologic factors in refractory CRS [24], it is thus intriguing to postulate that for patients with such inflammatory burden, a comprehensive management plan should be considered which includes a more radical surgery together with antibiofilm therapy to remove all triggers of inflammation that aid maintains a vicious cycle of local inflammation [1].

The positive rate of BBF in our study was in line with some of the other studies using SEM [25-27]; the high odds ratio and wide confidence interval in our study suggest that there is a statistically significant association between biofilm formation and CRSwNP.

In our study, biofilms were also found in 4 (40\%) of the 10 patients in the control group; they were also detected on the nasal mucosae of normal controls in some studies [25-28], assuming that biofilms may be normal colonies of bacteria. Mladina et al. detected BBF on healthy sinus mucosa and suggested that BBF could be normal respiratory mucosal blankets that contain lots of bacteria and part of the mucociliary system [27].

It is sensible to presume that BBF may be present in nasal mucosae of all controls and CRSwNP patients as the common survival bacterial property.

Besides, the presented pathological features of bony osteitis in our study that included thickening of the periosteum, new formation of unorganized woven bone, and fibrosis were also similar to previous studies [23, 26, 2931]. For additional correlation assessment, we used the histopathological bony grade of Biedlingmaier, which was proposed as the most beneficial system for histopathological grading by Videler et al. [24]

Table 3 Endoscopic grading in both study groups

\begin{tabular}{|c|c|c|c|c|c|c|c|}
\hline \multirow[b]{3}{*}{ Endoscopic grading } & & \multicolumn{4}{|c|}{ Group } & \multirow[b]{3}{*}{$x^{2}(1)$} & \multirow[b]{3}{*}{$P$ value* } \\
\hline & & \multicolumn{2}{|c|}{ CRSWNP $(\boldsymbol{n}=45)$} & \multicolumn{2}{|c|}{ Control $(\boldsymbol{n}=10)$} & & \\
\hline & & $n$ & $\%$ & $n$ & $\%$ & & \\
\hline \multirow[t]{5}{*}{ Right side } & Grade 0 & 0 & 0.0 & 10 & 100.0 & 36.258 & $<0.001$ \\
\hline & Grade I & 5 & 11.1 & 0 & 0.0 & & \\
\hline & Grade II & 14 & 31.1 & 0 & 0.0 & & \\
\hline & Grade III & 24 & 53.3 & 0 & 0.0 & & \\
\hline & Grade IV & 2 & 4.4 & 0 & 0.0 & & \\
\hline \multirow[t]{5}{*}{ Left side } & Grade 0 & 1 & 2.2 & 10 & 100.0 & 32.083 & $<0.001$ \\
\hline & Grade I & 5 & 11.1 & 0 & 0.0 & & \\
\hline & Grade II & 13 & 28.9 & 0 & 0.0 & & \\
\hline & Grade III & 22 & 48.9 & 0 & 0.0 & & \\
\hline & Grade IV & 4 & 8.9 & 0 & 0.0 & & \\
\hline
\end{tabular}

Data are number $(n)$ and percentage (\%)

$x^{2}$ chi-squared statistic

${ }^{*}$ Chi-squared test for trend 

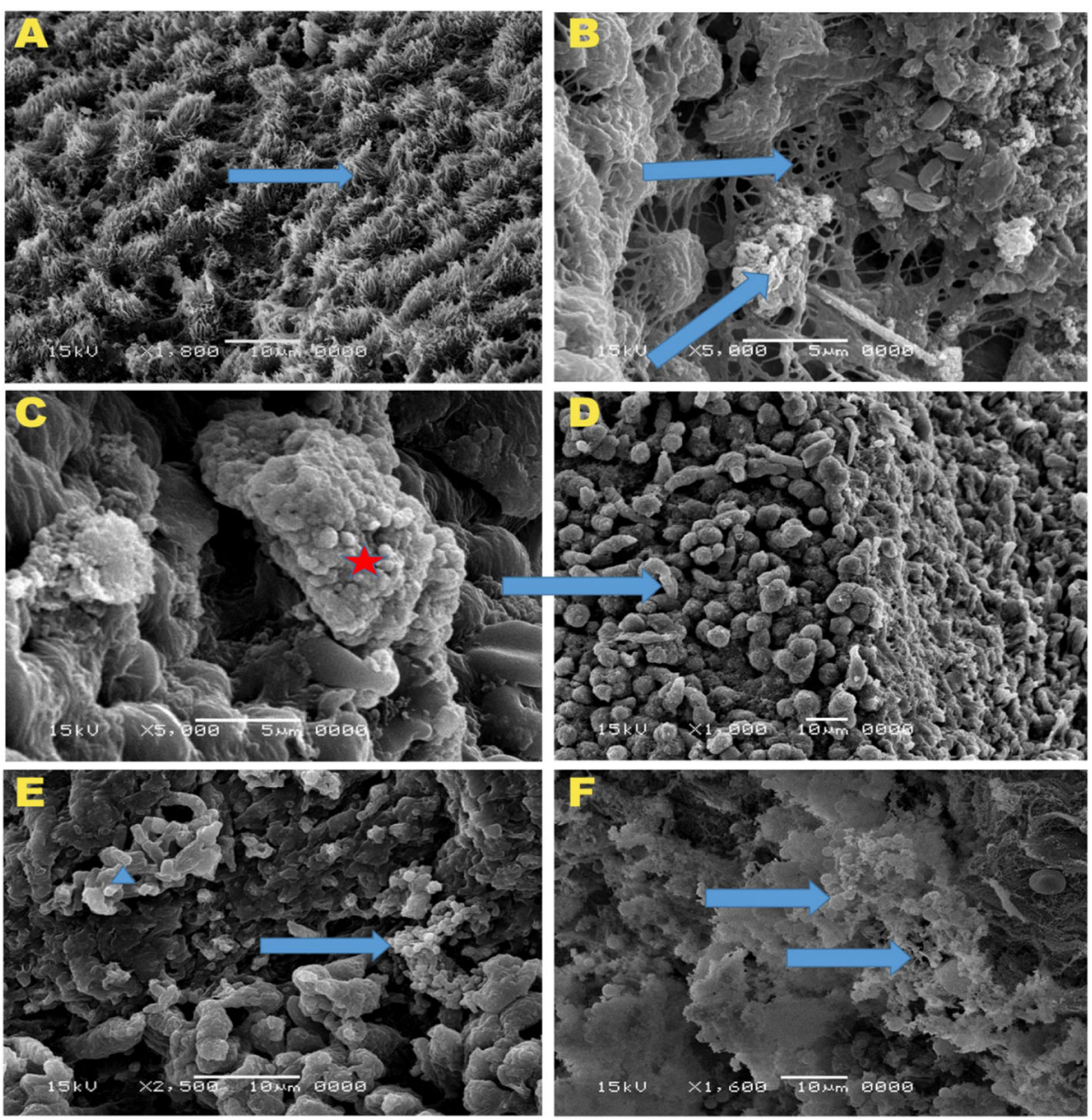

Fig. 1 (A) Normal cilia (arrow), (B) Biofilm structures embedded in matrix with water channels in between (arrows), (C) 3-Dimensional spherical biofilm structures embedded in matrix (star), (D) Non-ciliated swollen cylindrical epithelial cells (arrows), (E) 3-dimensional spherical biofilm structures with bacterial cocci (arrow), bacilli (arrow head),(F) 3-Dimensional spherical biofilm structures and water channels in between (arrows).

Our study displayed a positive correlation between bony osteitis and both mucosal grading (Spearman rho $=0.345, P$ value $=0.020)$ and tissue eosinophilia (Spearman rho $=0.294, P$ value $=0.049$ ), also a positive correlation between mucosal grading and tissue eosinophilia (Spearman rho $[\rho]=0.800, P$ value $<0.001$ ), which reflects the importance of inflammatory load in the disease development and maintenance.

Moreover, the presence of a positive correlation between biofilm and both bronchial asthma (phi coefficient $[\phi]=0.296, P$ value $=0.047$ ) and allergy (phi coefficient $[\phi]=0.394, P$ value $=0.021$ ) may suggest either both are predisposing factors for biofilms development or the role of intrinsic factors in biofilm development.

There was also a positive correlation between allergy and both the endoscopic grading (rank biserial correlation coefficient $=0.392, P$ value $=0.008$ ) and LundMackay score (point biserial correlation coefficient $=$
$0.394, P$ value $=0.007)$ which suggests the contribution of allergy in the disease severity.

There were also technical limitations in our study. First, the immunological characteristics of the mucosa that lies between mucosal biofilm and osteitic bone were not studied. Second, Foreman et al. [32] reported other methods as the noninvasive immunofluorescent demonstration of BBF, which will allow for both, leaving intact mucosa for additional study and also identifying the microbial species in BBF.

\section{Conclusion}

(1) Mucosal biofilms and osteitis were detected in patients undergoing FESS for CRSwNP and also in controls without CRS. This suggests that BBF and osteitis may not alone be the etiology of CRS without other cofactors. The pathogenesis of biofilms could be related to host factors. (2) The high odds ratio and wide confidence 
Table 4 Results of histopathological examination in both study groups

\begin{tabular}{|c|c|c|c|c|c|c|c|}
\hline \multirow[b]{3}{*}{ Variable } & & \multicolumn{4}{|c|}{ Group } & \multirow[b]{3}{*}{$x^{2}(1)$} & \multirow[b]{3}{*}{$\boldsymbol{P}$ value* $^{*}$} \\
\hline & & \multicolumn{2}{|c|}{ CRSWNP $(\boldsymbol{n}=45)$} & \multicolumn{2}{|c|}{ Control $(\boldsymbol{n}=10)$} & & \\
\hline & & $\bar{n}$ & $\%$ & $n$ & $\%$ & & \\
\hline \multirow[t]{4}{*}{ Bone grading } & Grade 0 & 5 & 11.1 & 4 & 40.0 & 1.074 & 0.300 \\
\hline & Grade I & 16 & 35.6 & 2 & 20.0 & & \\
\hline & Grade II & 19 & 42.2 & 2 & 20.0 & & \\
\hline & Grade III & 5 & 11.1 & 2 & 20.0 & & \\
\hline \multirow[t]{4}{*}{ Mucosal grading } & Grade 0 & 1 & 2.2 & 6 & 60.0 & 19.636 & $<0.001$ \\
\hline & Grade I & 8 & 17.8 & 2 & 20.0 & & \\
\hline & Grade II & 28 & 62.2 & 2 & 20.0 & & \\
\hline & Grade III & 8 & 17.8 & 0 & 0.0 & & \\
\hline \multirow[t]{4}{*}{ Tissue eosinophils } & Nil & 0 & 0.0 & 4 & 40.0 & 25.834 & $<0.001$ \\
\hline & Low & 3 & 6.7 & 4 & 40.0 & & \\
\hline & Moderate & 6 & 13.3 & 0 & 0.0 & & \\
\hline & High & 36 & 80.0 & 2 & 20.0 & & \\
\hline \multirow[t]{2}{*}{ Biofilm } & Negative & 8 & 17.8 & 6 & 60.0 & - & $0.012 \#$ \\
\hline & Positive & 37 & 82.2 & 4 & 40.0 & & \\
\hline
\end{tabular}

Data are number (n) and percentage (\%)

$x^{2}$ chi-squared statistic

${ }^{*}$ Chi-squared test for trend unless otherwise indicated

\#Fisher's exact test
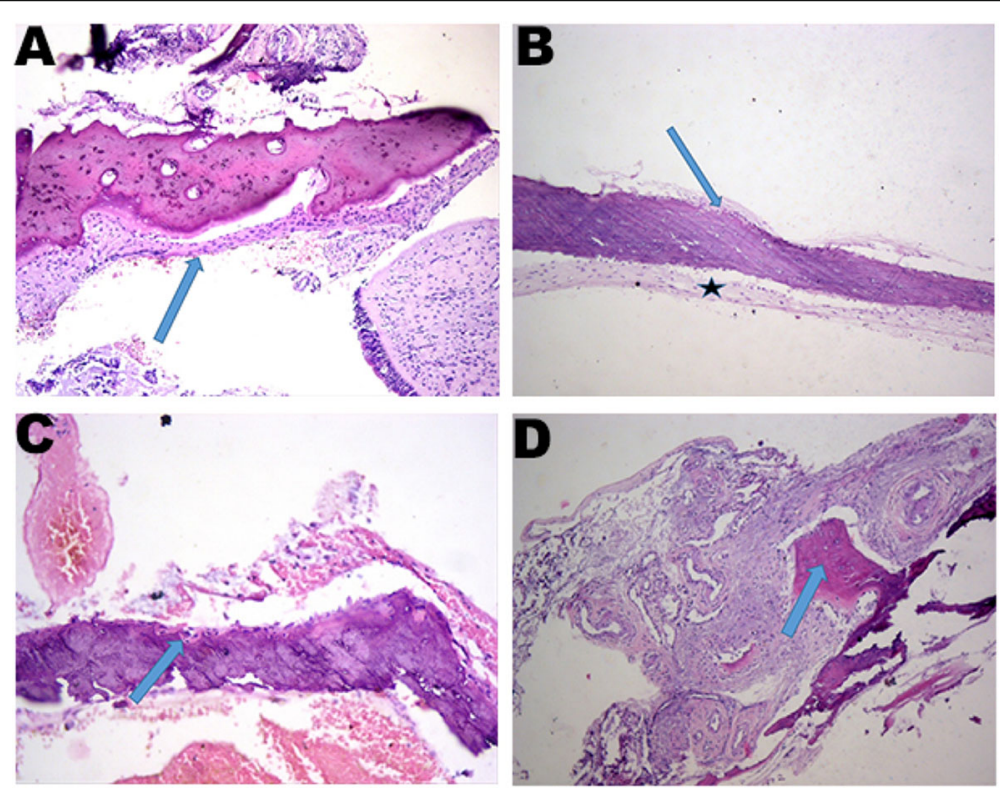

Fig. 2 a Bone grade I with periosteal thickening (arrow). b Bone grade II with periosteal thickening (star) and osteoblastic activity (arrow). c Bone grade II with osteoblastic and osteoclastic activity (arrow). d Bone grade III with irregular wide bony trabeculae (arrow) 

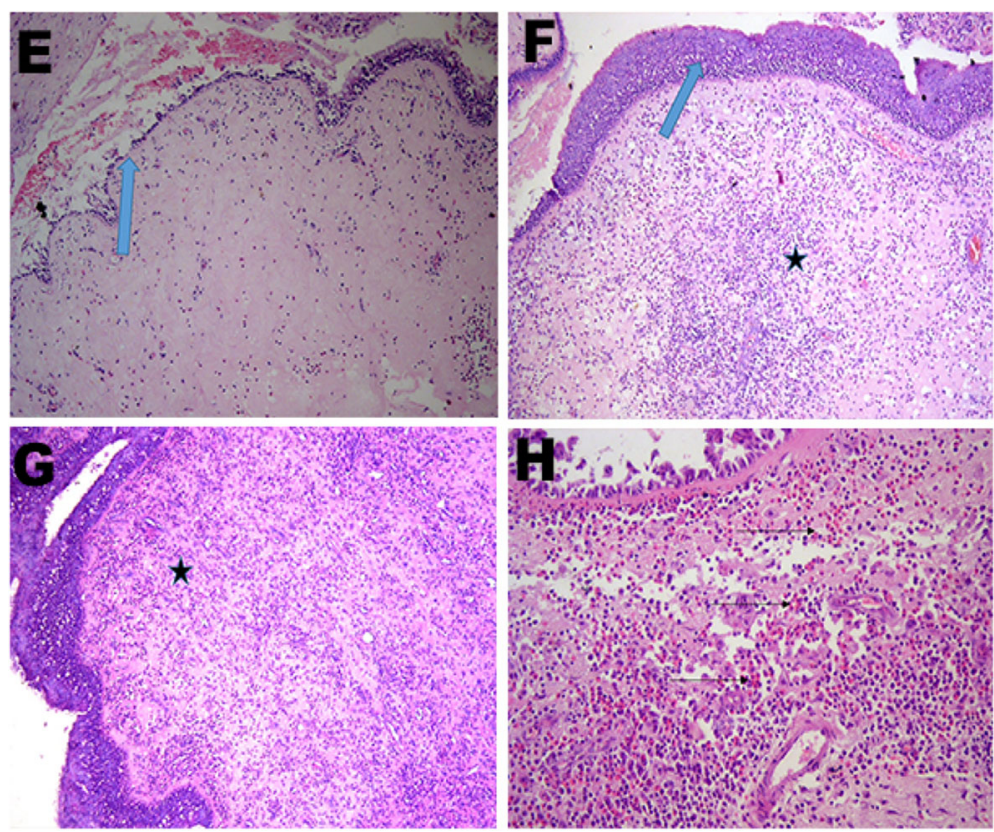

Fig. 3 e Mucosal grade I: mild inflammation (star) and focal degeneration of the epithelium (arrow). $\mathbf{f}$ Mucosal grade II: moderate inflammation (star) and hyperplastic surface epithelium (arrow). $\mathbf{g}$ Mucosal grade III: severe inflammatory cellular infiltrate (star). $\mathbf{h}$ Eosinophil rich inflammatory cellular infiltrate (arrows)

interval in our study suggest that there is a statistically significant association between biofilm formation and CRSwNP. (3) The high grade of mucosal inflammation and tissue eosinophilia suggests the inflammatory load added by osteitis and BBF.

\section{Abbreviations}

CRS: Chronic rhinosinusitis; CRSwNP: Chronic rhinosinusitis with nasal polyps; CRSsNP: Chronic rhinosinusitis without nasal polyps; BBF: Bacterial biofilm; CT: Computed Tomography; SNOT-22: Sinonasal outcome treatment score: HPF: High power field; SD: Standard deviation; SE: Standard error; SEM: Scanning electron microscope; FESS: Functional endoscopic sinus surgery; PBS: Phosphate buffered saline; 3D: 3-Dimensional; Cl: Confidence interval; FESS: Functional endoscopic sinus surgery; LMS: Lund-Mackay score

\section{Acknowledgements}

Not applicable.

\section{Authors' contributions}

TA: contributions to the conception and design of the work; the acquisition, collection, analyses, and interpretation of specimens and data of the work; wrote and drafted the work; and agreed both to be personally accountable for the author's contributions and to ensure that questions related to the accuracy or integrity of any part of the work, even ones in which the author was not personally involved, are appropriately investigated, resolved, and the resolution documented in the literature. NS: contributions to the conception, examined the specimens and revised the related part in the written draft and agreed both to be personally accountable for the author's contributions and to ensure that questions related to the accuracy or integrity of any part of the work, even ones in which the author was not personally involved, are appropriately investigated, resolved, and the resolution documented in the literature; EK and HI: substantively revised the manuscript ensure that questions related to the accuracy or integrity of any part of the work are appropriately investigated, resolved, and the resolution documented in the literature. The authors read and approved the final manuscript.

\section{Funding}

None.

\section{Availability of data and materials}

The datasets used and/or analyzed during the current study are available from the corresponding author on reasonable request.

\section{Ethics approval and consent to participate}

The ethical committee of Faculty of Medicine, Ain Shams University, Egypt, approved this work (registration-number: FMASU MD 466/2017). Informed written consent was obtained from all the participants.

\section{Consent for publication}

Not applicable.

\section{Competing interests}

The authors declare that they have no competing interests.

\section{Author details}

'Department of Otorhinolaryngology, Faculty of Medicine, Ain Shams University, Cairo, Egypt. ${ }^{2}$ Department of Pathology, Faculty of Medicine, Ain Shams University, Cairo, Egypt.

Received: 6 July 2020 Accepted: 2 August 2020

Published online: 02 September 2020

\section{References}

1. Bassiouni A, Naidoo Y, Wormald PJ (2012) When FESS fails: the inflammatory load hypothesis in refractory chronic rhinosinusitis. Laryngoscope 122:460-466

2. Chen HH, Liu X, Ni C, Lu YP, Xiong GY, Lu YY, Wang SQ (2012) Bacterial biofilms in chronic rhinosinusitis and their relationship with inflammation severity. Auris Nasus Larynx 39:169-174

3. Al-Mutairi D, Kilty SJ (2011) Bacterial biofilms and the pathophysiology of chronic rhinosinusitis. Curr Opin Allergy Clin Immunol 11:18-23

4. Foreman A, Jervis-Bardy J, Wormald PJ (2011) Do biofilms contribute to the initiation and recalcitrance of chronic rhinosinusitis? Laryngoscope 121: 1085-1091 
5. Foreman A, Boase S, Psaltis A, Wormald PJ (2012) Role of bacterial and fungal biofilms in chronic rhinosinusitis. Curr Allergy Asthma Rep 12:127-135

6. Singhal D, Foreman A, Jervis-Bardy J, Bardy JJ, Wormald PJ (2011) Staphylococcus aureus biofilms: nemesis of endoscopic sinus surgery. Laryngoscope 121:1578-1583

7. Tan NC, Foreman A, Jardeleza C, Douglas R, Tran H, Wormald PJ (2012) The multiplicity of Staphylococcus aureus in chronic rhinosinusitis: correlating surface biofilm and intracellular residence. Laryngoscope 122:1655-1660

8. Li H, Wang D, Sun X, Hu L, Yu H, Wang J (2012) Relationship between bacterial biofilm and clinical features of patients with chronic rhinosinusitis. Eur Arch Otorhinolaryngol 269:155-163

9. Bhandarkar ND, Mace JC, Smith TL (2012) The impact of osteitis on disease severity measures and quality of life outcomes in chronic rhinosinusitis. Int Forum Allergy Rhinol 1:372-378

10. Georgalas C (2013) Osteitis and paranasal sinus inflammation: what we know and what we do not. Curr Opin Otolaryngol Head Neck Surg 21:45-49

11. Lee JT, Kennedy DW, Palmer JN, Feldman M, Chiu AG (2006) The incidence of concurrent osteitis in patients with chronic rhinosinusitis: a clinicopathological study. Am J Rhinol 20:278-282

12. Saylam G, Gorgulu O, Korkmaz H, Dursun E, Ortapamuk H, Eryilmaz A (2009) Do single-photon emission computerized tomography findings predict severity of chronic rhinosinusitis: a pilot study. Am J Rhinol Allergy 23:172-176

13. Snidvongs K, McLachlan R, Sacks R, Earls P, Harvey RJ (2013) Correlation of the Kennedy Osteitis Score to clinico-histologic features of chronic rhinosinusitis. Int Forum Allergy Rhinol 3:369-375

14. Bhandarkar ND, Sautter NB, Kennedy DW, Smith TL (2013) Osteitis in chronic rhinosinusitis: a review of the literature. Int Forum Allergy Rhinol 3:355-363

15. European Position Paper on Rhinosinusitis and Nasal Polyps Group, Fokkens W, Lund V, Mullol J. EP3OS (2007) European position paper on rhinosinusitis and nasal polyps 2007. A summary for otorhinolaryngologists. Rhinology 45: 97-101

16. Biedlingmaier JF, Whelan P, Zoraski G, Rothman M (1996) Histopathology and CT analysis of partially resected middle turbinates. Laryngoscope 4:102-106

17. Snidvongs K, Lam M, Sacks R et al (2012) Structured histopathology profiling of chronic rhinosinusitis in routine practice. Int Forum Allergy Rhinol. 2(5):376-385

18. Wood AJ, Fraser J, Swift S, Amirapu S, Douglas RG (2011) Are biofilms associated with an inflammatory response in chronic rhinosinusitis? Int Forum Allergy Rhinol 1:335-339

19. Foreman A, Holtappels G, Psaltis AJ, Jervis-Bardy J, Field J, Wormald PJ, Bachert C (2011) Adaptive immune responses in staphylococcus aureus biofilm-associated chronic rhinosinusitis. Arerugi 66:1449-1456

20. Hekiert AM, Kofonow JM, Doghramji L et al (2009) Biofilms correlate with $\mathrm{TH} 1$ inflammation in the sinonasal tissue of patients with chronic rhinosinusitis. Otolaryngol Head Neck Surg 141:448-453

21. Sun $Y$, Zhou B, Wang $C$ et al (2012) Biofilm formation and toll-like receptor 2, tolllike receptor 4, and NF-kappaB expression in sinus tissues of patients with chronic rhinosinusitis. AmJ Rhinol Allergy 26(2):104-109

22. Tan L, Psaltis A, Baker LM, McGuckin M, Rousseau K, Wormald PJ (2010) Aberrant mucin glycoprotein patterns of chronic rhinosinusitis patients with bacterial biofilms. Am J Rhinol Allergy 24:319-324

23. Dong D, Yulin Z, Xiao W, Hongyan Z, Jia L, Yan X, Jia W (2014) Correlation between bacterial biofilms and osteitis in patients with chronic rhinosinusitis. Laryngoscope 124(5):1071-1077

24. Videler WJ, Georgalas C, Menger DJ, Freling NJ, Van drunen CM, Fokkens WJ (2011) Osteitic bone in recalcitrant chrionic rhinosinusitis. Rhinology 49:139-147

25. Bezerra TF, Padua FG, Gebrim EM, Saldiva PH, Voegels RL (2011) Biofilms in chronic rhinosinusitis with nasal polyps. Otolaryngol Head Neck Surg. 144: 612-616

26. Al-Madani AM, Helal SM, Khalifa HM, Abdelnaby MM (2016) Impact of osteitis and biofilm formation and correlation between both in diffuse sinonasal polyposis in Egyptian adults; a prospective clinical and histopathologic study. Alexandria J Med 52:243-250

27. Mladina R, Skitarelic N, Music S, Ristic M (2010) A biofilm exists on healthy mucosa of the paranasal sinuses: a prospectively performed, blinded, scanning electron microscope study. Clin Otolaryngol. 35(2):104-110

28. Jung JH, Cha HE, Kang IG, Kim ST (2015) Clinical Characteristics of Biofilms in Patients with Chronic Rhinosinusitis: A Prospective Case-Control Study. Indian J Otolaryngol Head Neck Surg. ; 67(1):1-6
29. Giacchi RJ, Lebowitz RA, Yee HT, Light JP, Jacobs JB (2001) Histopathologic evaluation of the ethmoid bone in chronic sinusitis. Am J Rhinol 15(3):193-197

30. Cho SH, Min HJ, Han HX, Paik SS, Kim KR (2006) CT analysis and histopathology of bone remodeling in patients with chronic rhinosinusitis Otolaryngol Head Neck Surg 135(3):404-408

31. Snidvongs K, Earls P, Dalgorf D, Sacks R, Pratt E, Harvey RJ (2014) Osteitis is a misnomer: a histopathology study in primary chronic rhinosinusitis. Int Forum Allergy Rhinol. 4(5):390-396

32. Foreman A, Jervis-Bardy J, Boase SJ, Tan L, Wormald PJ (2013) Noninvasive staphylococcus aureus biofilm determination in chronic rhinosinusitis by detecting the exopolysaccharide matrix component poly-Nacetylglucosamine. Int Forum Allergy Rhinol 3(2):83-88

\section{Publisher's Note}

Springer Nature remains neutral with regard to jurisdictional claims in published maps and institutional affiliations.

\section{Submit your manuscript to a SpringerOpen ${ }^{\circ}$ journal and benefit from:}

- Convenient online submission

- Rigorous peer review

- Open access: articles freely available online

- High visibility within the field

- Retaining the copyright to your article

Submit your next manuscript at $>$ springeropen.com 